\title{
Cultivate the Ability to Freehand Sketch
}

\author{
Zhao Feng \\ The university of Jinan civil construction institute \\ Jinan, Shandong, CHINA \\ Email: 2188871@163.com
}

\author{
$\mathrm{Fu} \mathrm{Jia}$ \\ The university of Jinan civil construction institute \\ Jinan, Shandong, CHINA \\ Email: fujia0531@163.com
}

\begin{abstract}
This article to junior architectural design course teaching as the background, review in the teaching link of freehand sketch effect, thinking how to the existing mature syllabus conditions, attach importance to training and freehand sketch communication ability training, get rid of computer development on architectural design teaching devour sex influence, in order to students' future career have a positive impact.
\end{abstract}

Keywords- freehand sketch; Architectural design; Course teaching

The Portuguese architect Alvaro Siza said: "when I visited the scene, I began to design. Design from a concept, and reciprocating back and forth in the first draft ". [1] Architects use sketches to analysis and elaboration construction, from Concept Generation start to detail completion end. Freehand sketch is the gateway to "Finished" in the process of continuously explore, discover and create journey. Compared to the other way, freehand sketch is intuitive and untrammeled.

In the design process, because of the architect ideas can change and need further, freehand sketch is a very important material and method to help architects keep the mind clear in the design process. All of the great buildings are originated from the architect's clear and imaginative decision in the

earlier stage of the design, and often these decisions are using sketch design to reveal out, the formation of the sketch design and its idea marks a creative leap. What is clear is that it is so important to a architect to have a intentions clear, characteristic sketch.

Construction class specialized students in grade two begin to contact the architectural design, the establishment and training of a good professional habit and professional accomplishment, It is the significant particularly important in the design of career first time the significant particularly important. Freehand sketch its emphasis on is not only the unarmed performance ability strong and the weak, it is emphasized a process from sketch to "Finished", and the information with infinite future and uncertainty of Sketch.

\section{THE POWER OF SKETCH}

\section{A. The Architect Visiting Card}

Architectural design is not only a requirement has rigorous logic thinking work, it is a challenging and creative art activities. The architect should accept function, material, structure and rational condition as the design framework, and must have the flexibility, liberal artists heart temperament. Throughout ancient and modern, Chinese and western traverse, the construction sector famous masters can unskilled computer mapping software, but no one will not retained enough to the design under the manuscript.

Unarmed performance as fast effective design performance techniques, not only design the intentions of the external display, it is also a way to show designers' culture and the culture of intuitive way. Architects use freehand sketch to weigh the modelling of architecture, architectural plane relationship, building space in the feeling, building in the field of the relationship, construction details, etc. Each architect with sketch hash architectural design habits and methods are different, the use performance vocabulary and to express emphasis is also different, there is very few two architects of the manuscript showed similarity. Good unarmed works not only has good perspective, organization, observing ability, still should reflect the designer to the space shape and pursue, it infiltrates the designer's personal characteristics, which makes the design works are more unique artistic appeal. Observation architects sketch can clearly understand their design style and design centre of gravity, and their reference point, his personality, even his emotions, like the composer for style, painter for school, the architect unarmed expression, is present personal information "visiting card", it is the architect part of language, (figure 1)but also the architect housekeeping skills and professional skills of the mark.

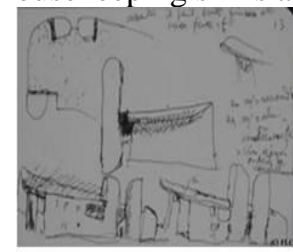

Le Corbusier

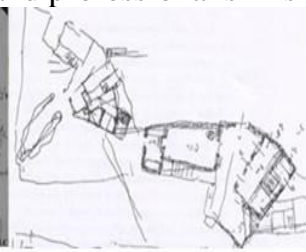

Siza

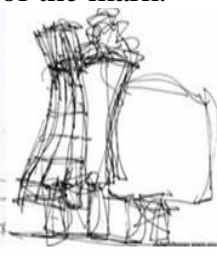

Frank Gehry
Figure 1. Sketch of Architects

\section{B. Free Thought}

The development of digital technology greatly expand the ways and means of architectural design, computer mapping accurate precision is freehand drawing to defeat, but in the architectural design process, especially the process of hash scheme, digital mapping but easy to restrict the development of design thinking. Also, since the operation proficiency, software itself development limited, and other factors, the designer must be in a certain extent subject to software. And freehand sketch is different, it 
convenient operation, the designer can focus on design work itself.

Free ideas need have a pair of follow one's inclinations hands on the expression of incisively and vividly. The initial design is to mind the idea into any kind of visible form, freehand sketch is undoubtedly one of the most convenient choice, it helps us will be fleeting and the idea of inspiration quickly record down, also is our rich image thinking and abstract thinking as early as possible for the performance of the visual image. The beginning of the scheme is often only one idea, sometimes just is a fuzzy concept or framework, other times perhaps only a small amount of detail, how the little information to accurately express way, seize the creation of aura, at this moment need not only is there free thought, but also have a pair of can follow thought free expression hands. Sketch can let architects of a single image under the brush, gush out, and then through the rational thinking and analysis to become mature. Therefore, having a pair of real freedom of hands, the mind of the designer can be realized and release.

\section{Appreciating Cultivation}

Architectural design in addition to structure, material, function have clear requirements, and a very important share, that is the pursuit of beauty. Good architecture is a long time not show its beauty, its beauty comes from its material composition, lighting changes, space structure, internal and external conversion, etc., is rational work process to the beauty of life of the pursuit of the results. Don't say and Ming, as building designer, must have elegant aesthetic ability, and cultivate the future architects aesthetic ability is very important.

Painting and architecture design in form aesthetic aspect to have the common pursuit, so architecture a grade opened the art class, for the subsequent freehand drawing lay a foundation, but also for the foundation of aesthetic culture. When we through continuous strict painting modelling training understand the law of formal beauty and able to skillfully use we space imagination ability and aesthetic ability and gained greater ascension. Therefore, in the identify any a thing of beauty and ugliness, we have the force of habit and judgment basis. In this sense freehand sketching ability strong and the weak will directly related to us in building design of space imagination and modelling aesthetic consciousness. On unarmed ability training, also is the aesthetic ability training.

\section{FREEHAND SKETCH TRAINING IN TEACHING REFLECT} AND GRASP

\section{A. The Plight of Reality}

The use of computer to architecture has deeply affected the development. Students after graduation into the unit of choose and employ persons have to use all kinds of computer software, such as Cad, Sketchup, etc., even during study period, along with to the architectural design thorough development, all kinds of competition that comes with the final mapping requirements are all kinds of computer drawing, freehand sketch into a passive and awkward dilemma. Many students because of freehand drawing of the fear or for faster skilled software purpose, early to give up free expression, into the arms of the computer. Even in drawing process, also use all kinds of quick modeling software, lost a lot of sketching practice and unarmed the opportunity to exchange. Therefore, in the realistic demand and talents appeared between the time of the competition dilemma, how can ensure that students master computer software, in order to get used to the work proposed mapping request, and can cause the student to the free exercise generate enough attention, it is what we should be treated seriously in the teaching process.

\section{B. The Training Process}

Students through the art of study, through the line drawing, color and fine art appreciation of a series of course, contact construction drawing and construction of all kinds of painting, such as watercolor, liquid powder, mark pen, color pencil, etc., and through the art practice opportunities, make sketchy ability get exercise and improve. In the Practice week, ruled out other courses and other external factors of interference and concentrate on improving the aesthetic cognitive ability and free expression ability. (figure 2)

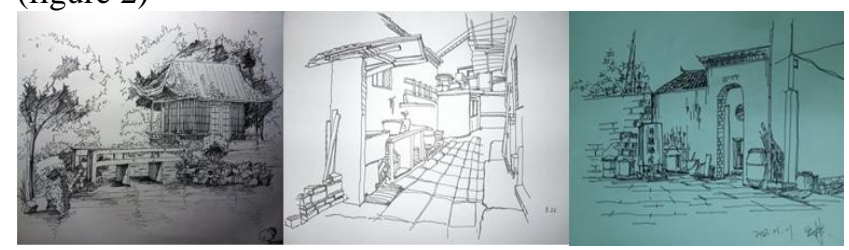

Figure 2. The student works

\section{The Beginning of Construction Work}

Villa design as architecture speciality the second grade students of the first design, to accept a grade building foundation after training courses for students really get in touch with the architectural design of the first design topic. Design topic is actually a utopian home, environment and other exterior restrictive condition is not much, important is to let the students into the field of design. Because the students lack of basic design concepts and design experience, the first architectural design course teaching need to guide students to learn from building the preliminary drawing expression type thinking to independent analysis, active creative thinking transformation. In architectural design curriculum teaching process, freehand sketch can assist teachers and students with better dialogue, communication, it is not only a kind of help teachers in the teaching constantly thinking and creation tools, more important is a live demonstration way to inspire students' learning and thinking methods. Can better master and cultivate the basic design method, will affect the students in the future architectural design course.

Design class students are required to use sketches and teachers to communicate, and in further study in the process of each stage are submitted to the sketch stage, namely progress check students' "a grass" "two grass". Architectural educationist, points out that the beauty of architecture 
learning process is not simple knowledge accumulation: "the best way to learn is personal experience, experience is more important than learning". In the course of teaching emphasizes the importance of "process design", through the sketch exchange the experience learning process intensification draft position.

Villa design last mapping also require students to use freehand drawing manner first design work, the purpose is to make the student to the unarmed mapping has certain cognitive, able to flat, stand, cutting, such as rendering chart has detailed analysis and elaboration, further strengthen the "experiential learning" the effect.

\section{Free Development}

In the face of the society various competitions, we in the spirit of encouraging attitude to promote students' participation. In counseling competition works in the process, still want to use the sketch to communicate. Therefore, competition to provide for students a course external professional communication opportunity, also make the students' comprehensive quality improved. In the process, students not only in complete entries for promoting, and in the face of other colleges and universities work, get cross. It's an opportunity to communicate the incomparable.

\section{EPILOGUE}

Sketch training is a long-term process, and not in one day can acquisition, this process may take several years, dozens of years or even the whole life. From learning architecture major, will be on the self-cultivation way.

As an architect in the future, independent thinking and communication is very important. Freehand sketch, As architects notes detailed and straighforward records this one phase of each process, and affect the final results of the design.

Second-year architectural design course as a student design career start. We have the responsibility and obligations laid its a good professional habit and professional accomplishment foundation. Encourage and urge students to sketch stick to it. And in the teaching process make it understand that Freehand sketch is not only convenient straightforward and the ability to relate to others, is the architect business card, free thought is blossom path, but also a good way to cultivate one's morality raises a gender as a "human being".

\section{REFERENCES}

[1] Le,Kang and Wang,Fangii. The sketch design thinking [J]. World Architecture, 2010 (1). 108-111.

[2] Feng,Gang. Architecture education theory of "freehand performance" teaching [J]. National architectural education academic conference, 2010024, - 245.

[3] Mao,Bing and Xue,Xiaowen. Building painting shows [M]. Shanghai: Tongji Univerity Press, 2004. 46-49. 